\title{
The Integration of the Virtual Business Incubation Services at the Conventional Business Incubator Center
}

\section{Qambar $\mathbf{M}^{\star}$}

Department of Business Administration, University of Bahrain, Zallaq, Bahrain

\begin{abstract}
The aim of this study is to evaluate whether the recent proposal for facilitating the virtual business incubation services at the Business Incubator Centers in the Kingdom of Bahrain is effective. The study is focused on determining the impacts of expected virtual business incubation services on the applicants, incubates and the management of business incubator centers. It further goes on to analyzing this data whether the virtual services can be facilitated at the business incubator centers in the Kingdom of Bahrain or not worth to use this kind of online services. This study employed the descriptive research method using a quantitative approach. Descriptive research technique is used to get information concerning the current status of the situation to describe what exists concerning variables or conditions in the present circumstances. The data was gathered from the questionnaires carried out through the structured survey. Descriptive survey method was used since this study focused on the determination of the extent of important level of internal and external factors encountered and what surround applicants, incubates and the management of the Business incubator centers in Kingdom of Bahrain. The proposed recommendation or suggestions considered include improvement of the performance and increase the chances of success for the entrepreneurs in the business incubator centers in Kingdom of Bahrain. The study displays the indications of the future potential in facilitating the virtual incubation services and the way of improving the services quality at the Business Incubator Center (BIC).
\end{abstract}

Keywords: Business incubation services; Business incubator; Virtual business incubation services; Services provider; Incubates; Entrepreneurs; Entrepreneurship; Business incubator in Bahrain

\section{Introduction}

This research focused on the virtual business incubation services and the possible benefits gained from the integration between the virtual business incubation services at the traditional business incubator centers in the Kingdom of Bahrain [1]. The virtual business incubation center would provide applicants, members, incubates, and entrepreneurs the necessary business incubation services in an online platform. This integration of the Virtual Business Incubation services and the conventional Business Incubator services would improve the efficiency of incubation services that would result to better quality, performance, and output. Business Incubator Center (BIC) is one of the business industry tools that support the economic development of Bahrain. It helps the budding and mature entrepreneurs for a start up a business - commercializing their ideas and eventually putting them in a business structure. Its services include serving a wide range of communities, industrial and corporate segments and individuals by providing them the right tools, carefully guiding them on how to establish a business from planning up to its implementation. Besides, supporting them to be involved in the market effectively and how to stay in shape in a rigid competition [2]. Now that the international markets are growing, the demand for online virtual business incubation services is a massive call. It is quite different from the old style of providing the incubation services in a physical space and location by setting up a shop at the incubator's site. The virtual business incubator center provides several kinds of online services through its website. The very purpose of this research is to encourage more participation to Business Incubator Center in the Kingdom of Bahrain. In doing so, researcher began to evaluate projects in several aspects, from studying the profile of the applicant, his scientific and practical experience of establishing a business up to his keen interest in developing and be involved in the actual business. Further, collecting information about the origin of the ideas, discussing them with the applicant and learning how to establish requirements had all been done [3]. In the course of doing this study, the researcher had immersed with the Business Incubator Center for a number of months in actual and direct work to discover common issues related to it. One of the most important problems encountered was the lack of the number of employees at the Business Incubator Center which impeded the acceptance of applicants to the Business Incubator Center. The second obstacle was the location of the Business Incubator Center, and the third problem was the lack of timeliness of interview schedule to evaluate ideas and discuss details of the applicants' projects. Hence, this research would prove the significance of providing an efficient and flexible incubation services through the virtual incubation services center. This study assessed the business incubator applicant's success by facilitating access to services using the virtual business incubation services at Business Incubator Center located in the Kingdom of Bahrain. Specifically, it aims to answer the following questions: What is the status of the access to the facilitated services at the business incubator centers located in the Kingdom of Bahrain? What is the level of expectations of business incubators applicants on accessing the types of services provided by the business incubators in the Kingdom of Bahrain in terms of: A) Services Types B) Quality Dimensions C) Satisfaction among the applicants? What are the problems identified by the applicants in accessing the services of business incubator centers in Kingdom of Bahrain? What is the level of effectiveness of using the virtual incubation services at the conventional business incubator centers in the Kingdom of Bahrain as perceived by the applicants? What are the recommendations of this study towards the integration of the virtual

*Corresponding author: Qambar M, Department of Business Administration, University of Bahrain, Zallaq, Bahrain, Tel: +97339477491; E-mail: mohamed.qamber@gmail.com

Recieved July 24, 2018; Accepted August 08, 2018; Published August 15, 2018

Citation: Qambar M (2018) The Integration of the Virtual Business Incubation Services at the Conventional Business Incubator Center. J Entrepren Organiz Manag 7: 242. doi: 10.4172/2169-026X.1000242

Copyright: @ 2018 Qambar M. This is an open-access article distributed under the terms of the Creative Commons Attribution License, which permits unrestricted use, distribution, and reproduction in any medium, provided the original author and source are credited. 
business incubation services at the Conventional Business Incubator Center in the Kingdom of Bahrain? The research Objectives are to provide factual and useful information to incubation center applicants, incubates and entrepreneurs in the process of availing and accessing related services from incubation centers [4]. To lay down business incubation principles and model to prospective business incubation applicants and startup businesses. To propose a new structure for a specialized system of training based on knowledge and good practices in the management of high-tech businesses in the Kingdom of Bahrain through a network of regional training, seminars, and literature. To develop, test and implement an online training methodology for standard and personalized courses. To develop a simple virtual learning environment for continuous professional development of incubates entrepreneurs, and managers of innovative and high-tech SMEs. In the Hypothesis part, there is no significant relationship between the level of expectations on the types of quality services and the factors that influence the success of applicants of the business incubators in the Kingdom of Bahrain [5]. The Significance of Study Part: The findings from this study that would be considered useful to the following: The government of the Kingdom of Bahrain: The study aims to help the government as a decision maker to address the ways of promoting economic development, that can support the innovated and talented in the Kingdom of Bahrain through the e-Government website, and the alliances with the government programs through the ministry of labor and social development. Business Incubators in the Kingdom of Bahrain: There are many business incubators in the Kingdom of Bahrain that could use the results of this research to benefit and increase their success factors and to pose awareness to the entrepreneurs and the talented citizens to start a business. Researchers: The study would help researchers in concern with examining various factors on virtual business incubation services as highlighted from the output of this study and can further scrutinize and progresses of the identified key services quality. Business Incubators' Applicants: The study would benefit the applicants who are applying for the business incubation services. Individuals, Mothers, Maternity. Persons staying at home and using the Internet and online learning to benefit and can stay in touch with real jobs, improve their skills and develop professionally. Persons with disabilities: The VBIs would provide a unique opportunity for them to learn how to start a business through a virtual environment. The Scope of The study determined the type of services provided by the business incubator centers in the Kingdom of Bahrain for the period of calendar year 2016-2017. It sought to determine the types and quality of services provided by the business incubator centers in the Kingdom of Bahrain particularly on virtual business incubation services. Further, it sought to determine the influence of factors to the business success of the business incubator centers' applicants. The 100 respondents were randomly chosen among the business incubators applicants and incubate in the Kingdom of Bahrain with no limitation to age consideration. The research limitations included only business incubator centers' applicants located in the Kingdom of Bahrain who applied for the business incubation services and the incubates positioned before the pre-incubation stage. It did not include other applicants outside of Bahrain [6] (Supplementary Figure 1) (Supplementary Table 1).

\section{Method}

The Virtual business incubator framework was proposed during the study, as illustrated in the framework, the process of business incubation starts from the pre-pre-incubation stage where registering in the virtual business incubation services website is required then the applicants are led in a pathway to know how to write the business plan to start ahead [7]. In preparation, training is conducted by providing a him the e-learning materials and resources to understand the business plan, marketing plan, financial calculations and they can find proper way to discover funding resources to start the business. There are advisors located during each step in the process, support them by e-channels, or it can be face-to-face meeting to find the best solution for their problems or questions [8]. The next stage it will be in the incubation stage, starting to get the resources of funding and it will depend on the kind of business, the forum it will be always there for general discussions or for getting an idea of others experiences shared online and can be accessible to the public for more benefit [9]. Even the e-books, researchers, publications, articles and other useful documents, it will be stored in the website library as a reference for the applicants to benefit from the others thoughts and experience. There is a hidden process in some areas of the framework that the admin of the website can approve or reject the projects to move to the next process or the next stage. Each step needs authorization from the admin to make sure that the applicant is moving in the proper path and method. The acceptance of the project type or the idea it will be in the beginning during the registration process, that the consultant can categorize the idea in which category can be fit to the BIC policy [10]. The Research Design of This study employed the descriptive research method. Descriptive research technique is used to get information concerning the current status of the situation to explain what exists about variables or conditions in the current conditions. The data was collected from the questionnaires carried out through a structured survey. Descriptive survey method was used since this study focused on the determination of the extent of important level of internal and external factors encountered with or surround applicants of Business incubator centers in Kingdom of Bahrain and the proposed recommendation or suggestions that be considered to improve the performance and increase the chances for the entrepreneurs in the business incubator centers in Kingdom of Bahrain. The respondents of this study were the incubates and the applicants of business incubator centers located in the Kingdom of Bahrain before the pre-incubation stage, both male and female [11]. Out of the estimated total population of the applicants and incubates in entire business incubators in Kingdom of Bahrain, a stratified sample of 100 respondents were chosen. The sampling design, due to the structured and formal nature and the presence of clearly stated hypothesis and investigative questions, this study used the descriptive type of research. The study is descriptive because the purpose of this study was to measure the effectiveness of integration and the using of the virtual business incubation services at the business incubator centers in Kingdom of Bahrain. For the validity of the Instrument In this study, the researcher viewed the possible potential respondents in the Kingdom of Bahrain and the decision to choose the applicants of business incubator centers in the Kingdom of Bahrain to answer the questionnaire. The questionnaire was reviewed and amended by the thesis advisor. Softcopies of the survey sent by SMS, WhatsApp and e-mailing system to most of the members, applicants, and tenants of business incubators in the Kingdom of Bahrain. The questionnaire was in Arabic and English for more accurate response and feedback [12]. The primary instrument which was used for gathering data is a survey questionnaire which is the sufficient tool concerning time to collect such data and according to the limitation that was encountered during the development of this study. The survey was adopted and modified it depends on the type of data required to reach the aim of this study to prove the benefits of using the virtual business incubation services at the conventional business incubator centers [13]. The questionnaire was composed of five parts. The first 
part was about the status of the access to the facilitated services at the business incubator centers located in the Kingdom of Bahrain. The second part described the level of expectations of business incubators applicants on accessing the types of services provided by the business incubators in the Kingdom of Bahrain. Third Part was about the problems do the applicants identified to access the services in business incubator centers in the Kingdom of Bahrain. Fourth part is to find the applicant's consideration of using the virtual incubation services at the conventional business incubator centers in the Kingdom of Bahrain. The last part was the recommendation that can be proposed to increase the applicant's satisfaction and improve them practice at the business startups [14]. The questions were structured by using Likert Scale. There was five selection provided to the respondents for every question or statement which based on the level of effectiveness in which the answer will be anchored in their perception to the concerned statement or question. The scale below was used to interpret the total responses for every problem by computing the average mean. Data Gathering Procedure, the questionnaires were distributed to the one hundred participants of business incubators. The target participants are familiar with the issues and questions included in the questionnaire [15]. This provided the researcher the chance to collect the accurate response and to conduct observations. Data Processing and Statistical Treatment, The Data collected was edited and coded for VBI services proposed to be integrated with conventional BICs. The mean was calculated to determine the respondent average perception on the different variable investigated. The weighted mean was used as the statistical tool in this study which is defined as an average was calculated by giving different weights to some of the individual values. Statistical Treatment of Data, The data gathered was organized, analyzed and interpreted using the MS spreadsheet (Microsoft Excel) containing high-level functions and tools in finding the mean, median, and mode. In the statement of problem, the average mean was used to find the applicants and incubates' satisfaction at the business incubator centers in the Kingdom of Bahrain in terms of types of services gained from the virtual business incubation services. The average mean was used to find the status of the access to the facilitated services at the business incubator centers located in the Kingdom of Bahrain. The average mean was used to find analyze the level of expectations of business incubators applicants on accessing the types of services provided by the business incubators in the Kingdom of Bahrain in terms of service types, quality dimensions, and satisfaction among the applicants. The problems the applicants have identified to access the services in business incubator centers in Kingdom of Bahrain was determined through their feedback as indicated in the result [16]. The applicants' feedback on the proposed recommendations of the online services to be facilitated at the business incubator centers in Kingdom of Bahrain questions was evaluated and noted according to rank or priority. Analysis and Interpretation [17] (Supplementary Figures 2-5).

\section{Results}

This Part presents the analysis and interpretation of results regarding the integration of the virtual business incubation services at the Conventional Business Incubator Center, Kingdom of Bahrain. The survey results show that most respondents were young, between the ages of $18-25$ years' old which $57 \%$ of the entire population is. $50 \%$ of the whole respondents are in college, $80 \%$ of them do not own a business, and $88 \%$ from the respondents are willing to establish a new business in the future, Respondents' Ages Summary are 57\% for 1825 Years old and 26\% for 36-50 Years old [18]. The Lowest rates for education level are 14\% for 25-35 Years old and 3\% for 51+ Years old.
Education Level Summary for the respondents are 50\% for College education level from total respondents and $45 \%$ for Graduate Studies from total respondents, The Lowest rates for education level are 3\% for secondary education level from total respondents and 2\% for Other [19]. The results of the question if the respondents currently owned a business or not, that most of them they don't own a business with $80 \%$ from the entire respondents [20]. And only $20 \%$ of them they own their business, The result of the respondents for the question if they are planning to own a business in the future or not, most of them planning to hold a business with $88 \%$, the remaining they are not interested in owning a business with $12 \%$ only [21]. The Five-Likert Scale was used in the survey questionnaires, in the first part about the status of access to the facilitated services of the business incubator centers located in the Kingdom of Bahrain. Where respondents agreed with a composite mean of 2.07 about the ongoing status of accessing the facilitated services of the business incubator centers located in the Kingdom of Bahrain [22]. Total respondents agreed that current leadership training and coaching services are slightly effective with mean 2.12 as an average, with 2.18 for the provided business plan development support services, with 1.98 for the training in innovative problem-solving techniques, the highest average is with 2.23 for the project management training and coaching services, with 2.05 for the financial management training and coaching services, with 2.20 for the legal matters and issues training and coaching services, with 2.02 for the marketing management training and coaching services, with 2.08 for the HR management training and coaching (staffing) services, The lowest average is with 1.81 for the strategic management training and coaching services, overall the average 2.07 which is slightly effective [23]. In part 2 on the level of expectations of business incubators applicants in accessing the types of services provided by business incubators in the Kingdom of Bahrain. Where respondents agree with a composite mean of 2.03 about the level of expectations of business incubators applicants in accessing the types of services provided by business incubators in the Kingdom of Bahrain. In part 3 on the problems of applicants identified in accessing and availing the services of business incubator centers in the Kingdom of Bahrain, the total respondents agreed that current mediation with partner's services provided by the business incubator centers Slightly Satisfied with mean 1.97 as an average, The Mediation with Customers with mean 1.94, The Mediation with Suppliers with 2.06, Mediation with Employees (staffing) with mean 1.95, the Mediation with University Researchers with 2.16 as the highest average of the entire list, the Mediation with Financiers with 2.07, the Capital through Equity Investment with 2.06 as an average [24]. The total average for this part is 2.03 which are slightly satisfied as responder's feedback from the expectation part. In part 3 the degree of problems applicants identified in accessing and availing the services of business incubator centers in the Kingdom of Bahrain, where respondents agree with a composite mean of 2.46 about the considered problems that applicants identified in accessing and availing the services of business incubator centers in the Kingdom of Bahrain [25]. Total respondents agreed that difficulties of accessing the business incubator center's location with mean level of 2.55, The Lack of time for attending workshops \& seminars with 2.00 , difficulty of getting appointment for advisory services with 2.64 as the highest mean in this part, The difficulty in hot desk space reservation with 2.51, The Delay in approval of incubator management for consultation services with 2.58 , The Missing the business incubators' events announcement with 2.49 , The higher rental rate at business incubator center with 2.57 and the difficulties of availing financing mediation services with 2.46 . The total mean average is 2.46 , that considered that the problems rate is slightly high depends on the respondents' feedback. In part 4 On the effectiveness 
of using the virtual incubation services at the conventional business incubator centers in the Kingdom of Bahrain, where respondents agree with a composite mean of 3.94 about the effectiveness of using the virtual incubation services at the conventional business incubator centers in the Kingdom of Bahrain [26]. The highest mean considered by the respondents is about the Using of online training sessions and materials with mean 4.19 that is very effective tool approved by them. Using the online coaching with mean 4.00 , using the online funding crowdfunding with 4.02 , the Using the online consultation interview with 3.88, the using the online discussion forum with 3.97, the using the online appointment system for getting a services from the Business Incubation Center with 4.00 , the using the online database storage for managing the incubation transaction services information with 3.93, the using online registration services with 4.16 , and the using online shop facility to purchase tools and equipment needed to establish an incubation center with 3.33 as the lowest mean in this part [27]. The Total mean average is 3.94 , that considered that the effectiveness of using the virtual incubation services at the conventional business incubator centers in the Kingdom of Bahrain rate is effective to depend on the responder's feedback [28,29] (Supplementary Tables 2-5) (Supplementary Figures 6-9).

\section{Discussion and Conclusions}

The major findings of the study are; the status of the access to the facilitated services at the business incubator centers located in the Kingdom of Bahrain is found to be Slightly Effective with average mean 2.07. All the respondents agreed that current leadership training and coaching services are slightly effective with mean 2.12 as an average, with 2.18 for the provided business plan development support services, with 1.98 for the training in innovative problem-solving techniques, the highest average is with 2.23 for the project management training and coaching services, with 2.05 for the financial management training and coaching services, with 2.20 for the legal matters and issues training and coaching services, with 2.02 for the marketing management training and coaching services, with 2.08 for the HR management training and coaching (staffing) services, The lowest average is with 1.81 for the strategic management training and coaching services, overall the average 2.07 which is slightly effective. The level of expectations of business incubators applicants on accessing the types of services provided by the business incubators in the Kingdom of Bahrain is found to be Slightly Satisfied with average mean 2.03. All respondents agreed that current mediation with partner's services provided by the business incubator centers Slightly Satisfied with mean 1.97 as an average, The Mediation with Customers with mean 1.94, The Mediation with Suppliers with 2.06, Mediation with Employees (staffing) with mean 1.95, the Mediation with University Researchers with 2.16 as the highest average of the entire list, the Mediation with Financiers with 2.07, the Capital through Equity Investment with 2.06 as an average. The total average for this part is 2.03 which are slightly satisfied as responder's feedback from the expectation part. The problems do the applicants identify to access the services in business incubator centers in Kingdom of Bahrain are found to be Slightly High with average mean 2.46. All respondents agreed that Difficulties of accessing the business incubator center's location with mean level of 2.55, The Lack of time for attending workshops \& seminars with 2.00, Difficulty of getting appointment for advisory services with 2.64 as the highest mean in this part, The Difficulty in hot desk space reservation with 2.51 , The Delay in approval of incubator management for consultation services with 2.58, The Missing the business incubators' events announcement with 2.49, The Higher rental rate at business incubator center with 2.57 and the Difficulties of availing financing mediation services with 2.46.
The Total mean average is 2.46 that considered that the problems rate is slightly high depending on the responder's feedback. The applicant's feedback on the proposed recommendations of the online services to be facilitated at the business incubator centers in Kingdom of Bahrain is found to be Effective with average mean 3.94. The highest mean considered by the respondents is about the Using of online training sessions and materials with mean 4.19 that's very effective tool approved by them. Using the online coaching with mean 4.00 , Using the online funding (Crowdfunding) with 4.02, the Using the online consultation interview with 3.88 , the Using the online discussion forum with 3.97, the Using the online appointment system for getting a services from the Business Incubation Center with 4.00, the Using the online database storage for managing the incubation transaction services information with 3.93 , the Using online registration services with 4.16 , and the Using online shop facility to purchase tools and equipment needed to establish an incubation center with 3.33 as the lowest mean in this part. The Total mean average is 3.94 , that considered that the effectiveness of using the virtual incubation services at the conventional business incubator centers in the Kingdom of Bahrain rate is effective to depend on the responder's feedback. The research finding some conclusions are the using the online training sessions and materials were the highest rank in the recommendation list, this shows the meaning of the need for the online training sessions. The using online registration services should be activated in the most incubator center in the Kingdom of Bahrain, to improve the services to the applicants. The using the online funding (Crowdfunding) is the third point getting one of the highest ranks in the list of recommendation. It needs a specific process structure to improve the Crowdfunding services through the online services channel. The using the online appointment system for getting services from the Business Incubation Center is one of the primary functions in business incubation services to improve the startup's success, should be there in the online services, but it should be providing the physical area for interviews and individual cases for consultation. The using of the online discussion forum, it will help the applicants to discuss the most important topics and problems; it will make the applicants concentrate on their businesses and ideas, by gaining the experience from other applicant's, incubates and the expertise. The recommendations of the research split to four parts start with; the integration of the Virtual business incubation services at the business incubator center could be implemented in most business incubators in Kingdom of Bahrain. The applicants need to access the BIC services virtually to benefit from the kinds of services facilitated in BIC located in Kingdom of Bahrain, the technology booming creates most of the online services accessible from everywhere, specially that everyone owned a device connected to the internet. That will increase the quality of services, types of services and the satisfaction among the applicants. The Integration of the Virtual business incubation services at the business incubator center will avoid the current problem do the applicants identify to access the services in business incubator centers in Kingdom of Bahrain. The cost of the operation at business incubators will be reduced, or at least the capacity of accepting project will be increased, the outcomes quantity and quality should be improved depend to the quality standard during setup the new structure and system.

\section{Acknowledgment}

In the conduct of this research, a new experience was substantially gained. The researcher had a lot of difficult time to establish a comprehensive analysis of the study and had felt very stressful because of the limited period to accomplish it. Working on the thesis has been a long process in which the researcher had learned to be more disciplined and systematic. Sincere acknowledgment is presented to everyone who helped in successfully completing this thesis study. Finally, in this work all thanks to ALLAH, to my advisors Dr. Danilo C. Diotay and Dr. Manolo L. Anto, my esteemed university (AMA international University - Bahrain), also to Dr. 
Citation: Qambar M (2018) The Integration of the Virtual Business Incubation Services at the Conventional Business Incubator Center. J Entrepren Organiz Manag 7: 242. doi: 10.4172/2169-026X.1000242

Page 5 of 5

Essam Janahi, the Managing Director of UOB Business Incubation Center for his support and by providing his experience to support this research, even to my lovely family, for their love and support, and to everyone who in one way or another had made this research come to light.

\section{References}

1. Aernoudt R (2004) Incubators: Tool for Entrepreneurship? Small Bus Econ 23 127-135.

2. Browne A (2014) Virtual Incubation Supports for 21st Century Start-Ups. Regional Development Centre, Dublin 2014.

3. Moreira AC, Carvalho MFS (2012) Incubation of New Ideas: Extending Incubation Models to Less-Favored Regions. Entrepreneurship - Creativity and Innovative Business Models.

4. Aranha SA (2003) Incubators models. Info Dev Incubator Support Center Pontifical University Calolica: Brazil.

5. Bergek A, Norrman C (2008) Incubator Best practice: A framework. Tec Novation 28: $20-28$.

6. Zornic D (2011) Advantages and Limitations of Virtual Incubators - 9th International Conference on Knowledge, Economy \& Management Proceedings, Serbia.

7. Cross Border Virtual Incubator (2013) Optimizing the Entrepreneurship Ecosystem Erasmus Multilateral Project, Cooperation between Universities and Enterprises.

8. Muraga D (2013) Virtual Business Incubation, East African Style, Kenya

9. Dee N, Gill DE, Livesey TF, Minshall THW (2011) Incubation for Growth: A Review of the Impact of Business Incubation on New Ventures with High Growth Potential.

10. Global Forum (2013) Business Incubation Training Program.

11. Hackett SM, Dilts DM (2004) A Real Options-Driven Theory of Business Incubation. J Technol Transf 29: 41-54.

12. Hanadi M, Busler M (2011) The Development of Entrepreneurial Companies through Business Incubator Programs.

13. Oncioiu I (2013) Business Innovation, Development and Advancement in the Digital Economy. Dimitrie Cantemir Christian University, Romania.

14. Lalkaka R (2006) Technology Business Incubation: A Toolkit on Innovation in Engineering, Science and Technology, France, United Nations Educational, Scientific and Cultural Organization.
15. Lalkaka R (2001) Best Practices in Business Incubation: Lessons (yet to be) Learnt. European Union Belgian Presidency's International Conference on Business Centers: Actor for Economics \& Social Development Brussels.

16. Gozali L, Masrom M, Haron HN, Zagloel TYM (2015) A Framework of Successful E-Business Incubator for Indonesian Public Universities. AJTM 8 : 118-131.

17. Literature Review: Incubator Programs, Virtual School Readiness Incubator Project The Florida Institute of Education at the University of North Florida June 2007.

18. Chambers M, Serup EK (2011) Thematic Working Group, Report on Incubators for Creative Entrepreneurs, Vejle, Denmark.

19. Grigorian A (2010) An Analysis of the Match between Supply and Demand of Business Incubator Services: The Case of IT incubation in Armenia.

20. Nowak MJ, Grantham CE (2000) The Virtual Incubator: Managing Human Capital in the Software Industry. Res Policy 29: 125-134.

21. Ohame K (2000) The Invisible Continent: Four Strategic Imperatives of the New Economy. Nicholas Brealey Publishing, London, England.

22. Peters L, Rice M, Sundararajan M (2004) The Role of Incubators in the Entrepreneurial Process. J Technol Transf 29: 83-91.

23. Scaramuzzi E (2002) Incubators in Developing Countries: Status and Development Perspectives, Info Dev Program. The World Bank Washington, DC.

24. Teknologi Malaysia, Jalan Sultan Yahya Petra, Kuala Lumpur, Malaysia Universitas Tarumanagara, Jalan S. Parman No 1, Jakarta, Indonesia University of Indonesia, Depok Campus, West Java, Indonesia.

25. Ratinho T, Harms R, Groen AJ (2010) Technology Business Incubators as Engines of Growth: Towards a Distinction between Technology Incubators and Non-Technology Incubators.

26. Venture Capital Building the Next Phase of Economic Development in Bahrain Thomson Reuters.

27. Fecet T (2011) Lesson on Virtual Business Incubation Services. The Netherlands, Info Dev.

28. Ryzhonkov V (2013) Key Services of Business Incubation Program

29. Von Zedtwitz M (2003) Classification and Management of Incubators: Aligning Strategic Objectives and Competitive Scope for New Business Facilitation. IJEIM 3: 176-196. 